NBER WORKING PAPER SERIES

\title{
PARETO-IMPROVING CARBON-RISK TAXATION
}

\author{
Laurence J. Kotlikoff \\ Felix Kubler \\ Andrey Polbin \\ Simon Scheidegger \\ Working Paper 26919 \\ http://www.nber.org/papers/w26919 \\ NATIONAL BUREAU OF ECONOMIC RESEARCH \\ 1050 Massachusetts Avenue \\ Cambridge, MA 02138 \\ April 2020
}

We thank Doris Follini for many helpful discussions and the Gaidar Institute, Boston University, the University of Lausanne, the University of Zurich and the Swiss National Science Foundation (SNF), under project ID "Can Economic Policy Mitigate Climate-Change?", and the Swiss Platform for Advanced Scientific Computing (PASC), under project ID "Computing Equilibria in Heterogeneous Agent Macro Models on Contemporary HPC Platforms", for research support. None of these institutions influenced in any manner the research or results of this study. The views expressed herein are those of the authors and do not necessarily reflect the views of the National Bureau of Economic Research.

At least one co-author has disclosed a financial relationship of potential relevance for this research. Further information is available online at http://www.nber.org/papers/w26919.ack

NBER working papers are circulated for discussion and comment purposes. They have not been peer-reviewed or been subject to the review by the NBER Board of Directors that accompanies official NBER publications.

(C) 2020 by Laurence J. Kotlikoff, Felix Kubler, Andrey Polbin, and Simon Scheidegger. All rights reserved. Short sections of text, not to exceed two paragraphs, may be quoted without explicit permission provided that full credit, including $(\subset)$ notice, is given to the source. 
Pareto-Improving Carbon-Risk Taxation

Laurence J. Kotlikoff, Felix Kubler, Andrey Polbin, and Simon Scheidegger

NBER Working Paper No. 26919

April 2020

JEL No. F0,F20,H0,H2,H3,J20

\begin{abstract}
$\underline{\text { ABSTRACT }}$
Anthropogenic climate change produces two conceptually distinct negative economic externalities. The first is an expected path of climate damage. The second, which is this paper's focus, is an expected path of economic risk. To isolate the climate-risk problem, we consider mean-zero, symmetric shocks in our 12-period, overlapping generations model. These shocks impact dirty energy usage (carbon emissions), the relationship between carbon concentration and temperature, and the connection between temperature and damages. Our model exhibits a de minimis climate problem absent its shocks. But due to non-linearities, symmetric shocks deliver negatively skewed impacts, including the potential for climate disasters. As we show, Paretoimproving carbon taxation can dramatically lower climate risk, in general, and disaster risk, in particular. The associated climate-risk tax, which is focused exclusively on limiting climate risk, can be as large or larger than the carbon average-damage tax, which is focused exclusively on limiting average damage.

Laurence J. Kotlikoff

Department of Economics

Boston University

270 Bay State Road

Boston, MA 02215

and NBER

kotlikoff@gmail.com

Felix Kubler

University of Zurich

Plattenstrasse 32

CH-8032 Zurich

Switzerland

and Swiss Financial Institute

fkubler@gmail.com

Andrey Polbin

The Russian Presidential Academy

of National Economy

and Public Administration

82 Vernadskogo prosp 117517

Moscow Russian Federation

and The Gaidar Institute for Economic Policy

apolbin@gmail.com

Simon Scheidegger

University of Lausanne

Department of Finance

Extranef 234

CH-1015 Lausanne

Switzerland

simon.scheidegger@gmail.com
\end{abstract}




\section{Introduction}

Anthropogenic climate change produces two conceptually distinct negative externalities. The first is a higher expected (average) path of damages. The second is greater volatility in the economy's transition path. This paper focuses exclusively on the second externality. It does so via an overlapping generations (OLG) model with three distinct mean-zero, symmetric shocks. These shocks capture the man-made climate risks highlighted by Weitzman (2012), Golosov et al. (2014), Barnett et al. (2020), and others. The first shock determines whether the economy will use more or less dirty energy. The second shock exacerbates or mitigates the relationship between CO2 emissions and temperature. Finally, the third shock enlarges or shrinks the key parameter in the climate-damage function.

Our OLG model is intentionally bare bones to isolate the cost of each form of risk propagation. In the absence of climate shocks, our model produces minimal climate damage. Adding in the three shocks raises the potential for "climate disasters", which we define as a drop in aggregate consumption by more than one third relative to trend.

In our main calibration, with no carbon policy, but with the three sources of risk activated, the probability, as of time zero, of a climate disaster arising over the next 250 years is over 7 percent, and 9 percent over the next 500 years. We find that disasters can arise due to significant skewness in the distribution of damages, which reflects the net impact of the model's non-linear elements. There are two competing supply-side non-linearities in climate models. First, damages are assumed to be a non-linear, convex function of global average surface temperature. Second, the average surface temperature is modeled as a concave, specifically the logarithmic function of atmospheric CO2. In our model, supply-side convexity outweighs supply-side concavity in determining carbonrisk damages. Moreover, when it comes to the welfare effects of carbon risk, the skewed supply-side damages reinforce the skewed demand-side impact arising from risk aversion.

Our paper's primary goal is finding Pareto-efficient paths of carbon-risk taxes - carbon taxes whose raison d'etre is not to limit average carbon damage because average damage is intentionally modeled to be minimal, but to limit downside carbon risk. Unlike prior studies of optimal carbon taxation in the presence of uncertainty, our model features selfish overlapping generations (12, to be precise) rather than a single representative agent. Single agents proxy, in these models, for dynasties 
whose current and future members are altruistically linked. Assuming that the world consists of such distinct tribes, each of which cares deeply for its descendants and acts on their behalf, seems a strange starting point for modeling the opposite behavior. Indeed, distinct altruistic tribes, which love only their current and future members and care nothing for each other, would naturally free-ride on each other. However, they could easily elect a government to pursue their common interest. Thus, if such descendent-loving tribes existed, optimal carbon policy would surely already be in place. ${ }^{1}$ In short, modeling selfishness requires modeling selfishness. Purely self-interested generational behavior is, of course, the hallmark of OLG models, making life-cycle agents natural progenitors of carbon externalities, including climate risk. As shown in Kotlikoff et al. (2019), albeit in a deterministic setting, this more realistic modeling of household behavior can materially impact optimal carbon taxation by limiting tax policies to those achieving Pareto improvements. ${ }^{2}$

Ours is hardly the first quantitative analysis of uncertainty's importance to optimal carbon policy. Prior major studies include those cited as well as Brock and Hansen (2017), Gillingham et al. (2015), Jensen and Traeger (2014), Lemoine and Traeger (2016), Cai et al. (2018), Cai et al. (2013), Daniel et al. (2019), and Traeger (2019). ${ }^{3}$ Nor is our model the first to posit selfish, life-cycle behavior. Early OLG models that consider resource-extraction and the environment include Howarth and Norgaard (1990), Howarth and Norgaard (1992), Burton (1993), Pecchenino and John (1994), John et al. (1995) and Marini and Scaramozzino (1995), Howarth and Norgaard (1990), Howarth (1991a,b), Burton (1993), Kavuncu and Knabb (2005), and Bovenberg and Heijdra (1998, 2002); Heijdra et al. (2006). ${ }^{4}$ Howarth (1991a) considers, in general terms, how to analyze economic efficiency in OLG

\footnotetext{
${ }^{1}$ Furthermore, as shown in Kotlikoff (1983), intermarriage across tribes will lead to their altruistic linkage. Indeed, effective tribal altruistic linkage requires only one current or future member of a tribe to marry one current or future member of another a tribe. Hence, the single-agent model with dynastic intermarriage devolves, under realistic conditions laid out by Bernheim and Bagwell (1988), to a social planner problem, no different from that posited by Nordhaus. Such a planner would have already internalized and all carbon externalities and there would no problem. Moreover, if intergenerational altruism is not prevalent, and there is very strong evidence that it is not (see Altonji et al. (1992), Abel and Kotlikoff (1994), Altonji et al. (1997), and Altig et al. (2001)), invoking a mythical social planner to impose her answer is no answer. One can conjure an endless variety of such planners, each with her preferences over current and future generations. The result is an infinite number of "optimal" carbon policies, none of which recommends itself over the others.

${ }^{2}$ Kotlikoff et al. (2019) show that single-agent "optimal" tax solutions may not be Pareto efficient in otherwise identical OLG models. With heterogeneous agents, optimal taxation requires Pareto improvements. Otherwise, all tax schemes, including those that reduce particular agents to starvation, are admissible based on an entirely arbitrarily assumed form of social-planner preferences.

${ }^{3}$ See, e.g., Cai (2020) for a thorough review.

${ }^{4}$ Howarth and Norgaard (1990), positing a pure exchange model, and Howarth (1991b), using a two-period OLG model with capital, point out that policymakers can choose among an infinite number of Pareto efficient paths in the
} 
models in the context of technological shocks. This said, our model appears to be the first study of optimal carbon-risk tax policy in a large-scale OLG model with shocks both to the climate system and the macro-economy. We use our model to identify carbon policies that leave the welfare of current generations unchanged, raise the welfare of future generations by as much as 4 percent, and lower the probability of a climate disaster from 9 to 1 percent.

What is our precise definition of a generation's welfare? Here we follow Blanchard (2019) in focusing on the generation's expected lifetime utility computed as of time- 0 when the policy is initiated. For current generations, lifetime utility references remaining lifetime utility. Moreover, as in Blanchard (2019), Pareto improvements are defined with reference to expected lifetime utility. ${ }^{5}$

While achieving a Pareto optimum in terms of expected utility makes sense, there is an infinite number of such optima to consider, each with its carbon tax and revenue-sharing policy. ${ }^{6}$ Kotlikoff et al. (2019) use Auerbach and Kotlikoff (1987)'s figurative Lump-Sum Redistribution Authority to derive the largest uniform welfare improvement from carbon taxation across all current and future generations. This solution seems of focal interest because of the potential political appeal of uniform treatment. $^{7}$

To be precise, our optimal carbon-risk tax policy is set to minimize the chance of reaching a climate tipping point subject to achieving a Pareto improvement, where current generations are kept whole, in terms of their expected remaining lifetime utilities and all future generations experience expected lifetime expected utility gains, albeit, not necessarily uniform. In our model, optimal carbon-risk taxation raises future generations' expected utilities by up to 4 percent, depending on their year of birth, and it lowers the probability of crossing a calamitous climate tipping point from 9 to 1 percent. Moreover, the level of carbon-risk taxation is substantial compared to the carbon average-damage process of correcting negative environmental externalities. Gerlagh and Keyzer (2001); Gerlagh and van der Zwaan (2001) consider the choice among such Pareto paths and the potential use of trust-fund policies that provide future generations a share of the income derived from the exploitation of the natural resource. Gerlagh and van der Zwaan (2001) also point out that demographics can impact the set of efficient policy paths through their impact on the economy's general equilibrium.

${ }^{5}$ An alternative Pareto criterion is an ex interim improvement, where an agent is defined by the time and date-event of her birth (see, e.g., Krueger and Kubler (2006)).

${ }^{6}$ Revenue shares can be negative for some generations, meaning that total taxes of all other generations will exceed total carbon-tax revenues. Hence, our revenue-sharing scheme admits generalized intergenerational redistribution.

7 Kotlikoff et al. (2019)'s solution algorithm takes a particular time-path of carbon taxation as given and iterates over annual cross-cohort redistribution to achieve a uniform percentage improvement in utility/welfare measured as an equivalent percentage compensating consumption variation. It then searches over carbon-tax policies (the tax's initial level and fixed annual growth rate) to find the Pareto policy producing the largest uniform welfare gain. 
tax rate - the carbon tax needed when there is no uncertainty about its damage and its damage, under business as usual (BAU) — that is, no policy, produces a 15 percent decline in long-run output.

Unfortunately, achieving a uniform welfare gain in a stochastic OLG framework is computationally far more challenging. In addition, potentially very adverse future shocks can limit the scope for uniform welfare gains. ${ }^{8}$ Hence, we confine ourselves here to simply finding Pareto paths that materially reduce the chances of a climate disaster. ${ }^{9}$

Our policy instruments are a) a tax on dirty energy's use that is either time-invariant or depends on the level of carbon in the atmosphere and b) time-varying sharing of each period's tax revenues among concomitant generations. Revenue sharing is set, period by period, to ensure that current generations achieve the same expected utility as under the BAU scenario.

Specifically, a large enough share of revenues is allocated to the oldest generation in period 0 to ensure that it's expected utility is unchanged. All other generations receive the identical share, which may be negative. In period 1, the oldest generation's revenue share, which is the same regardless of the particular shocks it experiences over the rest of its life, is large enough to ensure that its expected remaining lifetime utility as of time 0 is unchanged. In period 1 , as in all subsequent periods, all younger (than the oldest) generations receive the same net share of carbon-tax revenues. This policy continues through period 12, after which tax revenues continue to be divided as they were in period 12. Once the economy switches entirely to green energy, carbon taxation, as well as the redistribution of carbon revenues, comes to an end. Also, note that the period-specific shares of revenues allocated through time to different generations are independent of the state of nature.

Our focus on limiting the chance of significant reductions in aggregate consumption is influenced by Barro and Ursua (2008). Their study collects country-specific historical data on significant declines in aggregate consumption. The findings suggest that drops of more than one third are very rare, are typically caused by wars, and generally have long-lasting effects on the regions in question.

Our stochastic OLG model is the barest of bones to focus full attention on the aforementioned three climate risks. The supply side of our model is similar to Cai et al. (2013) and Nordhaus (2017).

\footnotetext{
${ }^{8}$ Intuitively, if the gains to future generations are enormous because, say, they involve avoiding death, providing current generations with equal percentage expected utility gains as those coming in the future might require having them consume far more than the economy's capital stock. This would leave no capital for production and terminate the economy.

${ }^{9}$ We will return to this issue in future work, which will include state-dependent generational-redistribution policy.
} 
Final goods are produced using dirty energy, whose use emits CO2 into the atmosphere. Technological progress, captured by dirty energy's coefficient in the model's production function for output, leads, over time, to the crowding-out of dirty energy. Consequently, in the long run, only clean energy is used in production. Unlike Kotlikoff et al. (2019), clean energy is not explicitly modeled. Instead, it is implicitly treated as the economy's ability to produce, through time, with smaller and, ultimately, zero reliance on dirty energy.

We adopt the carbon cycle, and temperature equation posited by Golosov et al. (2014), which simplifies Nordhaus (2017)'s treatment of these elements. Following most of the related literature (see, e.g., Nordhaus (2017), and the references therein), we assume that higher temperatures lower total factor productivity. As Nordhaus (2008) points out, "the economic impact of climate change .. is the thorniest issue in climate-change economics". Weitzman (2012) adds a tipping point to the standard Nordhaus damage function, which has the damage function increasing dramatically for temperature increases beyond a given level. We follow his specification. Specifically, we posit that damages are the following function of excess temperature (defined as the global temperature increase), $T_{t}^{A}$ :

$$
D_{t}=1-\frac{1}{1+\left(\frac{1}{20.46} T_{t}^{A}\right)^{2}+\left(\frac{1}{6.081} T_{t}^{A}\right)^{6.754}} .
$$

This specification generates damages that are very similar to those in Nordhaus if the global mean temperature increases by less than 3 degrees Celsius relative to pre-industrial levels. For higher temperature increases, damages are significantly larger. Thus, a 3-degree temperature increase represents our model's tipping point. Such tipping points include losing most of the Amazon rain forest, faster onset of El Niño, the reversal of the Gulf Stream and other ocean circulatory systems, the melting of Greenland's ice sheet, the loss of Siberia's permafrost leading to massive methane gas release, and the collapse of the West Antarctic ice shelf. Each of these events would directly or indirectly lower productivity.

As indicated above, climate change uncertainty comes in three forms. First, dirty energy's share in the production function is subject to symmetric shocks as it trends to zero. Since these shocks can be negative as well as positive, CO2 emissions might remain high, at current or, indeed, higher levels, for an extended period or might decrease dramatically within a matter of decades. Second, the 
so-called climate-sensitivity parameter, which determines the increase in temperature arising from increases in $\mathrm{CO} 2$, is stochastic, meaning the sensitivity of temperature to carbon concentration can fall as well as rise. Third, the parameter for the quadratic term in the damage function, which governs the probability of crossing the tipping point in damages, is stochastic. We model all three processes as random walks.

We begin by solving the model with no uncertainty, assuming dirty energy is entirely supplanted by clean energy in 120 years. Using Weitzman (2012)'s damage function, damages from climate change are very small. Consequently, efficient, time-invariant dirty energy taxes are, in this context, quite minor as are the efficiency gains from carbon taxation. Stated differently, our model's optimal carbon average-damage tax is minor.

We assume throughout that agents' coefficients of relative risk aversion are 2. This is a moderatesized coefficient compared to that assumed in the literature (see, e.g., Cai (2020) and references therein). Nevertheless, since damages are skewed, and agents are risk-averse, the average welfare loss is significant. Indeed, as discussed, when all three shocks occur simultaneously, a simple scheme that imposes a carbon tax at $t=0$, which then increases significantly when temperature increases, can lead to substantial welfare gains for all generations. Initial generations only gain about 0.1 percent. Welfare gains become larger in about 100 years, generations born in 150 years gain about 4 percent and generations born in 200 years gain 5 percent. Welfare gains then slowly flatten to about 3 percent in the very long run.

The paper first focuses exclusively on dirty energy usage shock. Adding this shock does not change the expected end date of dirty energy usage. However, it does increase the chances that emissions remain high over the next 100 years. This, in turn, increases the potential for climate tipping. Our second experiment adds shocks to the climate-sensitivity parameter in addition to the energy-usage shocks. Energy-usage shocks turn out to be a prerequisite for generating climate disasters. The climate-sensitivity parameter plays a crucial role in modern climate modeling. Unfortunately, there is large disagreement about its value (see, e.g., Allen and Frame (2007), Forster et al. (2020), Knutti et al. (2017), or Roe and Baker (2007)). Based on our reading of the climate-science and economics literature, we model this parameter as a random walk with reflecting barriers, where we set the barriers to -30 and +30 percent around the mean. This shock, in conjunction with the usage shock, 
makes climate disasters much more likely, with their probability increasing above five percentage points. The time-invariant, Pareto-improving carbon taxes can help, but not enough to lower the climate-disaster probability below 2.7 percent for these two shocks,

Our final step is to add the damage-function parameter shock to the other two and, thereby, capture climate-damage tipping points. We assume that this parameter shock follows a random walk

with an upper reflecting bound and becomes fixed when the temperate reaches the tipping point. In presence of all three types of uncertainty, the model's disaster probability increases to almost 9 percent. With this degree of risk, substantially higher fixed (through time) carbon-risk taxes are Pareto-improving. Moreover, fixed carbon-risk taxes can reduce the probability of climate disasters to around 3 percent. However, as we demonstrate, having CO2-dependent taxes, the likelihood can be reduced below 1.5 percent.

The remainder of the paper is organized as follows: Section 2 presents our model. Section 3 discusses the calibration strategy and reports results for a baseline calibration without uncertainty. Section 4 considers the effect of uncertainty about dirty energy usage (equivalently, CO2 emissions). Section 5 add the CO2-temperature sensitivity shock. Section 6 presents the full model with all three shocks, stressing that the carbon-risk tax - the tax needed to handle carbon risk can be as large or larger than the carbon average-damage tax - the tax needed to handle average carbon damage. Section 7 concludes.

\section{Model}

Time is discrete and indexed by $t=0,1, \ldots$ In each period, a cohort of identical agents enters the economy, retires after 10 periods, and dies after 12 periods. A representative firm produces a single consumption good by using capital, labor, and dirty energy as inputs. Dirty energy is produced using capital and labor.

\section{$2.1 \quad$ Firms}

Final goods are produced via

$$
Y_{t}=A\left(D_{t}\right) K_{1 t}^{\gamma_{t} \alpha} L_{1 t}^{\gamma_{t}(1-\alpha)} E_{t}^{1-\gamma_{t}}
$$


where $Y_{t}$ is output, the price of which is normalized to 1 , and $A_{t}, D_{t}, K_{1 t}, L_{1 t}$, and $E_{t}$ refer to total factor productivity, climate damage, capital, labor, and dirty energy, respectively. The parameter, $\alpha$, is capital share. As detailed in subsection 2.4, dirty energy's factor share, $1-\gamma_{t}$, evolves stochastically as it trends toward 1. Its stochastic path captures our first shock - carbon-usage uncertainty.

Dirty energy is produced with capital and labor - that is, with no fixed or quasi-fixed factors. This is consistent with modeling in many studies, e.g. Cai et al. (2013). Since financial markets are incomplete and agents are heterogeneous, adding such factors or incorporating adjustment costs would bring the firm's objective function into question - that is, firms would no longer necessarily maximize period-specific profits since deviating from profit maximization might mitigate shareholders' future risks. Thus:

$$
E_{t}=K_{2 t}^{\theta} L_{2 t}^{1-\theta}
$$

where $K_{2 t}$ and $L_{2 t}$, respectively refer to capital and labor used in producing dirty energy. ${ }^{10}$ Final goods producers purchase dirty energy at the producer price, $p_{t}$, plus the carbon tax, $\tau_{t}$. Each period's revenue from the carbon tax is redistributed among concomitant generations. Capital depreciates at a rate $\bar{\delta}$, independent of whether it is used in the dirty energy or final goods sectors. CO2 emissions in period $t$ emissions are proportional to $E_{t}$ with a proportionality factor, $\iota$, calibrated to roughly match 2015 industrial emissions.

\subsection{Households}

The households live for $A$ periods. Those born at time $t$ maximize lifetime expected utility, given by

$$
U_{t}=\mathbb{E}_{t} \sum_{j=1}^{A} \beta^{j} \frac{C_{t+j-1, j}^{1-\sigma}-1}{1-\sigma},
$$

subject to

$$
C_{t, j}+a_{t+1, j+1}=\left(1+r_{t}\right) a_{t, j}+w_{t}-\theta_{t, j}
$$

where $\beta$ is the time preference factor, $C_{t, j}, a_{t, j}, w_{t, j}$ correspond to consumption, assets, and wages of generation $j$ at time $t$, respectively, and labor supply is normalized at 1 . The parameter $\theta_{t, j}$ denotes

\footnotetext{
${ }^{10}$ We normalize TFP in dirty energy production at 1 with no loss of generality.
} 
the possibly state-specific net tax paid by agent $j$ at time $t$. The allocation of capital between dirty energy and goods production is given by

$$
\sum_{j=1}^{A} a_{t, j}^{K}=K_{t}=K_{1 t}+K_{2 t} .
$$

Households born prior to $t=0$ maximize their remaining lifetime utilities.

\subsection{Modeling climate change as a negative externality}

We model the carbon cycle as in Golosov et al. (2014). Temperature in period $t$ is determined by the stock of carbon in the atmosphere, $S_{t}$,

$$
T_{t}=\lambda_{t} \frac{\log \left(S_{t} / S\right)}{\log (2)}
$$

where $S$ is the pre-industrial carbon stock. We model $\lambda_{t}$ as stochastic. ${ }^{11}$ Thus, $\lambda_{t}$ is our model's second key shock.

Following Golosov et al. (2014), we assume that the CO2 stock in the atmosphere has two components - that is,

$$
S_{t}=S_{1 t}+S_{2 t}
$$

where

$$
S_{1 t}=\phi \xi E_{t}+\delta_{S 1} S_{1, t-1}
$$

and where

$$
S_{2 t}=(1-\phi) \xi E_{t}+\delta_{S 2} S_{2, t-1}
$$

The depreciation parameters satisfy $\delta_{S 2}<\delta_{S 1}$, and we calibrate, the former at a low value and the later at a high value, again following Golosov et al. (2014). Hence, $S_{1 t}$ is a slowly depreciating stock of carbon, whereas $S_{2 t}$ is a rapidly depreciating stock. The parameters $\phi$ and $\xi$ control the fraction of $\mathrm{CO} 2$ emissions entering the atmosphere. We take $\phi, \xi$, and the depreciation parameters as fixed. Nevertheless, adding shocks to these variables makes little difference to our results.

\footnotetext{
${ }^{11}$ We specify its exact process in section 2.4 below.
} 
Weitzman (2012)'s formulation of the temperature damage function is given by

$$
D_{t}=1-\frac{1}{1+\left(\frac{1}{20.46} T_{t}^{A}\right)^{2}+\left(\frac{1}{2 T P_{t}} T_{t}^{A}\right)^{6.754}},
$$

where the term $T_{t}^{A}$ refers to global mean surface temperature relative to its 1900 value. The term $T P_{t}$ is our third shock. Weitzman calibrates $2 T P_{t}=6.081$ to be constant over time. This corresponds to a climate tipping point occurring at about 3 degrees excess temperature.

Climate change reduces output productivity according to

$$
A_{t}=\left(1-D_{t}\right) Z
$$

where $Z$ is the constant, non-stochastic production efficiency coefficient - that is, we ignore secular growth for the sake of simplicity.

\subsection{Stochastic processes}

We now specify the stochastic processes for the dirty energy share in the production function, $1-\gamma$, the climate sensitivity parameter, $\lambda$, and the tipping point, TP. We assume that all three follow random walks.

1. Innovation/Emissions Uncertainty:

$$
\gamma_{t}=\gamma_{t-1}+\epsilon_{\gamma t}
$$

for $\gamma_{t} \leq 1$ with $\epsilon_{\gamma t} \geq 0, \mathbb{E} \epsilon_{\gamma t}=0.04$, and $\gamma_{0}=0.9$. $\gamma_{t}=1$ is an absorbing state, which is reached, on average, in 120 years. To ensure a solution to the model, we assume $\gamma_{60}=1$ - that is, 300 years later, all dirty energy usage ends (although this can and typically will occur much earlier). This assumption captures the gradual decline in the use of dirty energy, punctuated by periodic new dirty energy discoveries that temporarily reverse this trend.

2. The second shock involves the degree to which higher CO2 translates into higher temperatures. 
Here we assume that the climate sensitivity parameter, $\lambda$, follows a random walk,

$$
\lambda_{t}=\lambda_{t-1}+\epsilon_{\lambda t}
$$

with $\epsilon_{\lambda_{t}}$ being i.i.d. with mean zero and reflecting barriers, namely lower and an upper bounds, $\underline{\lambda}$ and $\bar{\lambda}$.

3. The third form of uncertainty concerns damages, the uncertainty of which arises due to uncertainty in the model's tipping-point parameter, $T P$. We assume that as long as the actual temperature is below the tipping point, the latter follows a random walk with innovation $\epsilon_{T P^{-}}$ that is,

$$
T P_{t}=T P_{t-1}+\epsilon_{T P, t}
$$

where $\epsilon_{T P, t}$ is i.i.d. with mean zero, but with the stopping criterion. If, at some period t, atmospheric temperature, $T_{t}^{A}$, reaches the tipping point, $T P_{t}$, the tipping point remains fixed. Moreover, we assume that there are reflecting barriers - that is, there exists a lower, $\underline{T P}$, as well as an upper bound, $\overline{T P}$. These bounds ensure that the tipping point cannot be too low and that if temperature increases are extreme, a tipping point is reached eventually.

\subsection{Government}

In each period, the government imposes taxes on dirty energy use and distributes the revenues among extant generations. As indicated, carbon-risk taxation, as well as the distribution of carbon-risk revenues, cease when $\gamma_{t}$ reaches 1 .

We consider both time-invariant as well as carbon-dependent carbon-risk taxes. To find the optimal tax rate in the time-invariant case, we compute different tax rates on a grid. As explained in the introduction, for each tax rate, we implement transfers that use as much of the tax revenue as necessary to ensure that the old. in each period are held at their status quo. If the carbon tax rate is too high, our computation routine quickly rejects that solution. Instead of systematically searching for an "optimal" tax, we simply construct a nonlinear tax that performs significantly better than the fixed tax. 
In both the time-invariant and carbon-dependent carbon-risk tax cases, we couple the carbon taxation with time-changing, but state-invariant generation-specific sharing of carbon-tax revenue. Recall, that generation-specific revenue shares are adjusted in the first 12 periods to ensure that each initial cohort has the same expected remaining lifetime utility under the policy as without it. Furthermore, after the first 12 periods, revenue shares are held fixed at their values in period 12 . While nothing in our set up prevents negative transfers to particular generations, our solutions always generate positive time- but not state-specific revenue shares for each generation alive in each period of carbon taxation.

We choose the transfers and taxes to guarantee a Pareto-improvement for all current and future generations and to minimize the probability of climate disasters. This is equivalent to maximizing the tax rate under the constraint that no current or future generation loses. In practice, this means keeping current generations at their status-quo welfare (expected remaining lifetime utility) levels and improving the welfare levels (expected lifetime utility) of all future generations.

\subsection{Recursive formulation of the OLG model}

The aggregate state variables in our model are $S_{1 t}, S_{2 t}, \gamma_{t}, \lambda_{t}, T P_{t}$, and the aggregate capital stock, $K_{t}$. The optimal policies will be a function of the aggregate state variables, and the cross-generation distribution of cash on hand. Our computation technique is the projection method developed in Marcet (1988), Marcet and Marshall (1994), Marcet and Lorenzoni (2001), and Judd et al. (2011). Our implementation follows Krusell and Smith (1998), in general, and Kubler and Scheidegger (2019), in particular, by condensing the distribution of assets across agents into one state variable.

One perhaps novel element of our projection methodology is handling non-ergodicity ${ }^{12}$ in the early periods of the transition. Generally, simulation based methods are applied in settings in which only the ergodic distribution matters. In this case, one can draw a long time series of shocks, guess policy functions (in our case, consumption functions), project the economy forward for that long time series, use Euler conditions to determine optimal choices conditional on the guessed functions, and use the associated time series data on optimal choices and the state vector to update the guessed policy

\footnotetext{
${ }^{12}$ While the state-variables do follow a Markov process, some of the states (for $\gamma<1$ ) are transient and simulation based methods typically implicitly assume that all states of interest are recurrent.
} 
functions. Our problem is non-ergodic until dirty energy usage ceases. Hence, for these periods, we need to solve for period- and cohort-specific policy functions through period 300 conditional on dirty energy continuing to be used. This requires using cross-section as well as time series data.

Agents forecast their future consumption as a function of this condensed state variable and the aggregate states, and they choose an optimal investment based on these forecasts. In equilibrium, the forecasts are almost accurate (within a relative consumption error of at most $10^{-3}$, which translates directly into the relative error in consumption equivalent Euler equations). We approximate the forecasts numerically using Gaussian processes, and we solve for the forecasts using a simulationbased method. ${ }^{13}$

Government policies are a function of time and, potentially, the amount of carbon. For the computation of taxes and transfers, we, therefore, include calendar time, $t=0,1, \ldots$, as a state variable. Since the economy is non-stationary until only clean energy is used (i.e., until $\gamma_{t}=1$ ), it is crucial to simulate the first 60 periods (i.e., 300 years until we enforce $\gamma=1$ ) often to generate good approximations, particularly given the potential for rare events. (This is the just mentioned cross-sectional data requirement.) We find that 100 simulations of the first 60 periods typically suffice for good numerical results.

We fix initial conditions at $t=0$ by assuming that agents live in a deterministic economy with $\gamma=0.9$ but a constant level of CO2 in the atmosphere through $t=-5$ and then suddenly discover the potential for climate change.

Note that in our numerical results, we report probabilities of climate disasters obtained via Monte Carlo simulations. Specifically, we simulate the economy for 100 model-periods (corresponding to 500 years), starting at the initial condition. We repeat this simulation 5000 times, reporting the relative frequency of paths where a climate disaster occurs as the "probability" of a climate disaster.

\subsection{Welfare analysis}

The welfare of current and future generations is measured as their expected utility at time zero. We report welfare changes as consumption equivalents, i.e., given our CRRA specification for the utility function with a coefficient of relative risk aversion of $\sigma$, let $U_{t}$ denote expected utility of generation $t$

\footnotetext{
${ }^{13}$ for more details, we refer to Kubler and Scheidegger (2019).
} 
in the BAU scenario, and let $\tilde{U}_{t}$ denote expected utility with carbon taxes in place. We then compute the consumption-equivalent factor,

$$
\left(\frac{\tilde{U}_{t}}{U_{t}}\right)^{\frac{1}{1-\sigma}}-1
$$

The consumption-equivalent factor tells us the percentage higher or lower level of consumption an agent would require, in all states arising under BAU, to achieve the same expected utility as under the policy in question.

\section{Calibration}

Households live for twelve periods - that is, $A=12$, where each period corresponds to five years as in Nordhaus (2015). We assume that the capital shares in producing output and energy, $\alpha$ and $\theta$, respectively, both equal 0.3 . We set the capital depreciation rate, $\bar{\delta}$ to 0.2 . The coefficient of relative risk aversion, $\sigma$, is set to 2.0 , and the time preference factor, $\beta$, is 0.99 , leading to an average annual return to capital of about 3 percent. Moreover, through each agent's tenth period, we use a 12-period version of the age-earnings profile in Kotlikoff et al. (2019) and then assume agents work on a 35 percent basis in periods 11 and 12. Having agents continue to work at the end of life proxies for a state-pension system.

In addition, following Golosov et al. (2014), we fix $\xi$ at 0.4, and $\phi$ at 0.5. Recall from equations (8), (9), and (10) that $\xi$ determines, in part, the degree to which dirty energy production generates slowly as well as rapidly depleting atmospheric CO2. The coefficient, $\phi$, in turn, determines the shares of dirty energy emissions that end up as slowly or rapidly depreciating atmospheric CO2. The slow and fast depreciation rates, $\delta_{S 1}$ and $\delta_{S 2}$, are set at 1.0 and 0.99 , respectively. These parameters also coincide, on a period-adjusted basis, with those in Golosov et al. (2014). As in Golosov et al. (2014), we set $\lambda_{0}$ at 3.0, and following Weitzman (2012), we set TP $P_{0}$ at 3.04. Finally, we calibrate $\iota$, the emissions-proportionality factor, to match initial emissions to equal to 30 GtCO2/year (Nordhaus (2017) states that 2015 CO2 emissions from industrial activity were around 35.85 GtCO2/year $)^{14}$.

\footnotetext{
${ }^{14}$ Details on $\iota$ 's calculation are available from the authors.
} 

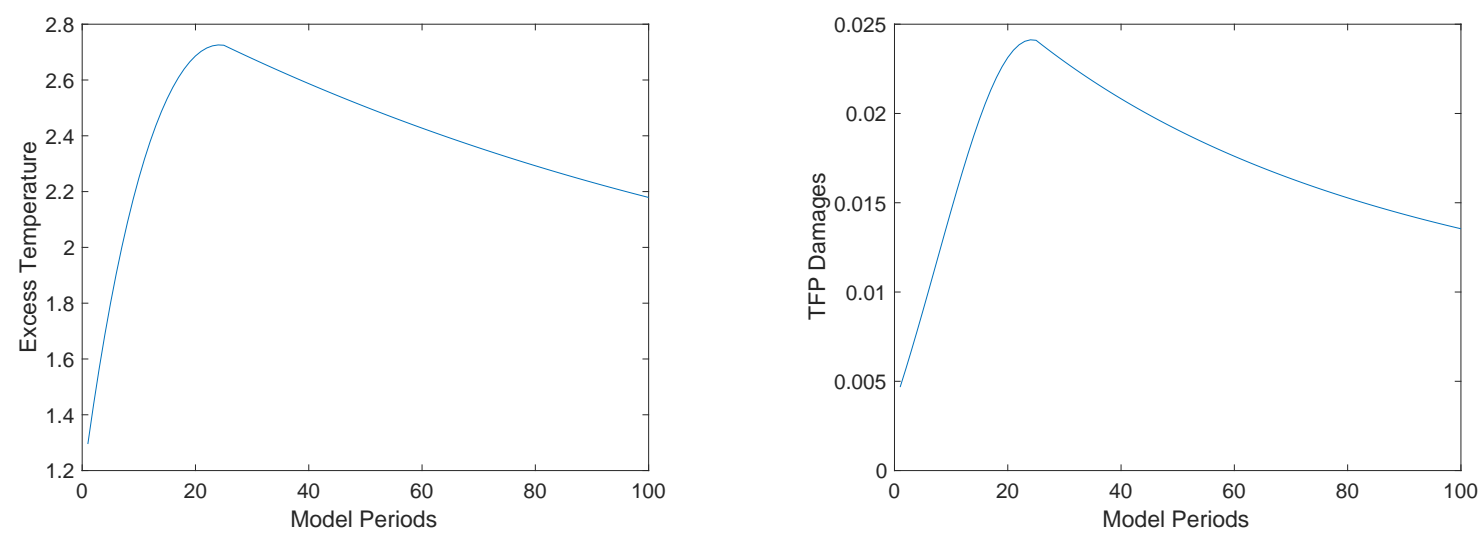

Figure 1: Temperature and damages over the next 500 years.

\subsection{Results for the deterministic benchmark case}

Our benchmark is the OLG model with no uncertainty. Thanks to the downward trend in $\gamma$, the solution entails $\mathrm{CO} 2$ emissions decreasing monotonically and reaching zero after 24 periods, i.e., 120 years. The maximum (excess) temperature is slightly below 2.8 degrees, and the maximum damages are less than 2.5 percent of final output. Figure 1 shows how the temperature and damages evolve over time.

The average return to capital in this baseline deterministic calibration is about 3 percent per year. Using a grid search and lump-sum inter-generational transfers as in Kotlikoff et al. (2019), we find an optimal uniform, welfare-improving carbon-tax of roughly 10 percent that increases the expected utility of all current and future generations by roughly 0.1 percent. Hence, in the absence of risk, there is essentially no scope/need for policy.

If we restrict the Pareto policy to a maximum uniform increase in the expected utilities of those born in the future, leaving the expected remaining lifetime utilities of initial $(t=0)$ generations, the optimal tax is less than 5 percent. It barely increases the expected utility of all future generations born after 100 years.

This paper's goal is to understand the importance of carbon risk. One means of making that assessment is to compare the sizes of optimal carbon taxes with and without such risk. As just 
indicated, absent shocks, our model suggests a quite limited role for carbon taxation. This is to be expected since all three of the model's key emission-generating parameters have zero means. However, the model also shows that the average path of carbon does not drive our results discussed below.

To compare the optimal carbon tax - the carbon average-damage tax - needed to deal solely with average emissions with that needed to deal solely with risky emissions - the carbon-risk tax, we need to specify a reasonable average path of emissions in our deterministic model. To do so, we set $\epsilon_{\gamma}$ to 0.02 . The transition to clean energy now takes 250 years (50 model periods) instead of 125 years above. Consequently, temperature increases by 4.5 degrees. This results in damages of about 10 percent of GDP after 150 years, peaking at about 18 percent of GDP after 250 years, and then slowly decreasing after that. Welfare losses to future generations are now substantial - the welfare of generations born in 150 years is about 6.5 percent lower than the welfare of agents born today. However, the highest tax rate compatible with not over-compensating current generations (the policy constraints maintained below) is only about 15 percent, which produces welfare gains of up to 3.5 percent for future generations born after 250 years $^{15}$.

\section{Uncertain CO2 emissions}

The crucial elements of uncertainty in our setup run through CO2 emissions and the possibility that the share of dirty energy remains large over the next 50 years or so. To model this issue, we assume, as explained above, that $\epsilon_{\gamma, t}$, the i.i.d. shock to dirty energy share has a positive variance. Moreover, after 60 periods - that is, 300 years, we set $\gamma_{60}$ to 1 if it has not reached this value already. The crucial aspect of this form of uncertainty is that it makes potential long-run damages much larger. Once CO2 is emitted, about 20 percent remains a permanent feature of the atmosphere. This, in turn, means permanent planetary heating, which implies permanent damages. We assume the following values for this shock:

$$
\epsilon_{\gamma t}= \begin{cases}-0.05 & \text { with probability } 0.4 \\ 0.05 & \text { with probability } 0.4 \\ 0.2 & \text { with probability } 0.2 .\end{cases}
$$

\footnotetext{
${ }^{15}$ Keeping initial generations whole and ending transfers when dirty energy usage ends rules out higher tax-rate policies that would more than compensate initial generations and, on balance, further help future generations by further improving their climate despite making them pay a larger fiscal bill.
} 
Moreover, we set $\underline{\gamma}=0.88$ as the reflecting lower boundary. This rules out dirty energy's production share rising significantly relative to the current status quo. Note that, on average, $\gamma$ increases by 0.04 in every period, as in the deterministic calibration above. However, it can vary substantially over time - clearly, in the worst-case scenario, it goes down to 0.88 and stays there for 60 model periods. However, this worst-case scenario has a probability of approximately 0 and can be neglected in our calculations.

While our formulation of the energy-usage shock lacks micro-foundations, it succinctly captures the qualitative features of this form of uncertainty. Further research, such as Acemoglu et al. (2016), may provide such foundations. Nevertheless, as we now describe, our exercise shows that a slow transition to clean energy can dramatically raise the probability of a climate disaster.

\subsection{Business as usual with shocks to dirty energy usage}

We now consider shocks simply to dirty energy usage, starting with the BAU equilibrium. Figures 2, 3, and 4 show the distribution of TFP-damages and temperatures for periods 20 (100 years), 40 (200 years) and 100 (500 years). All histograms show results for 1500 simulations. Note that major
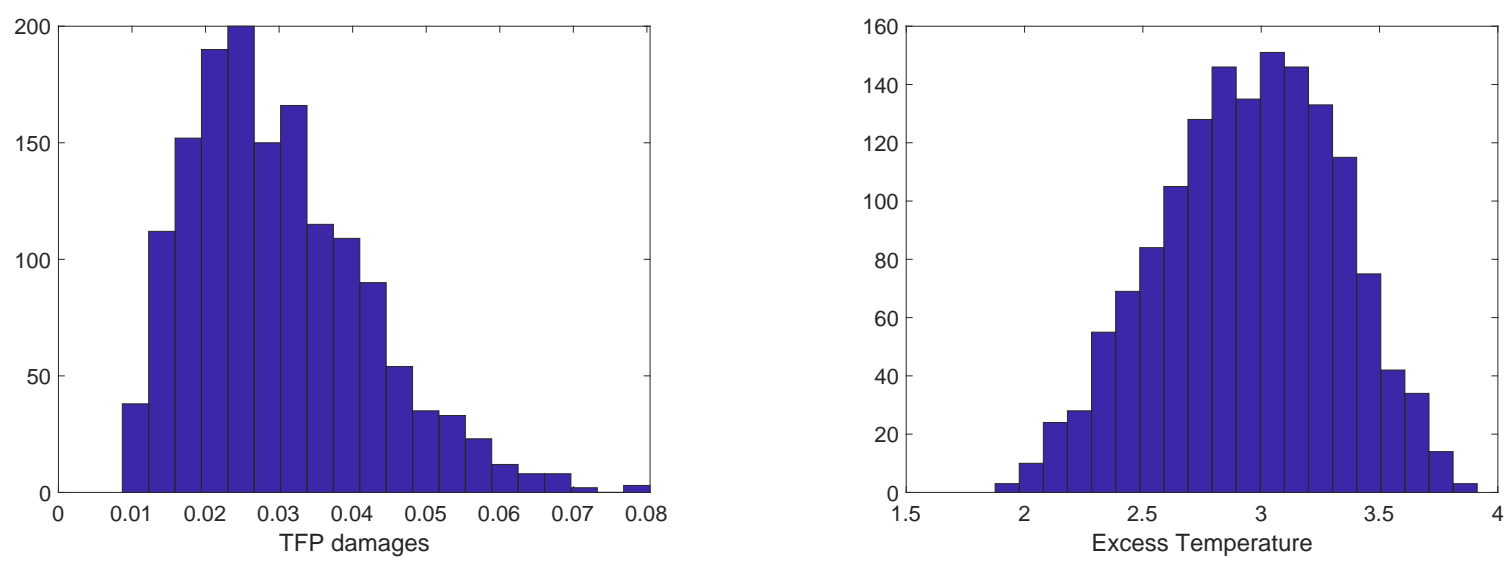

Figure 2: Distribution of damages and temperatures after 100 years.

economic damages can arise if dirty energy is used for an extended period. Since the transition to 

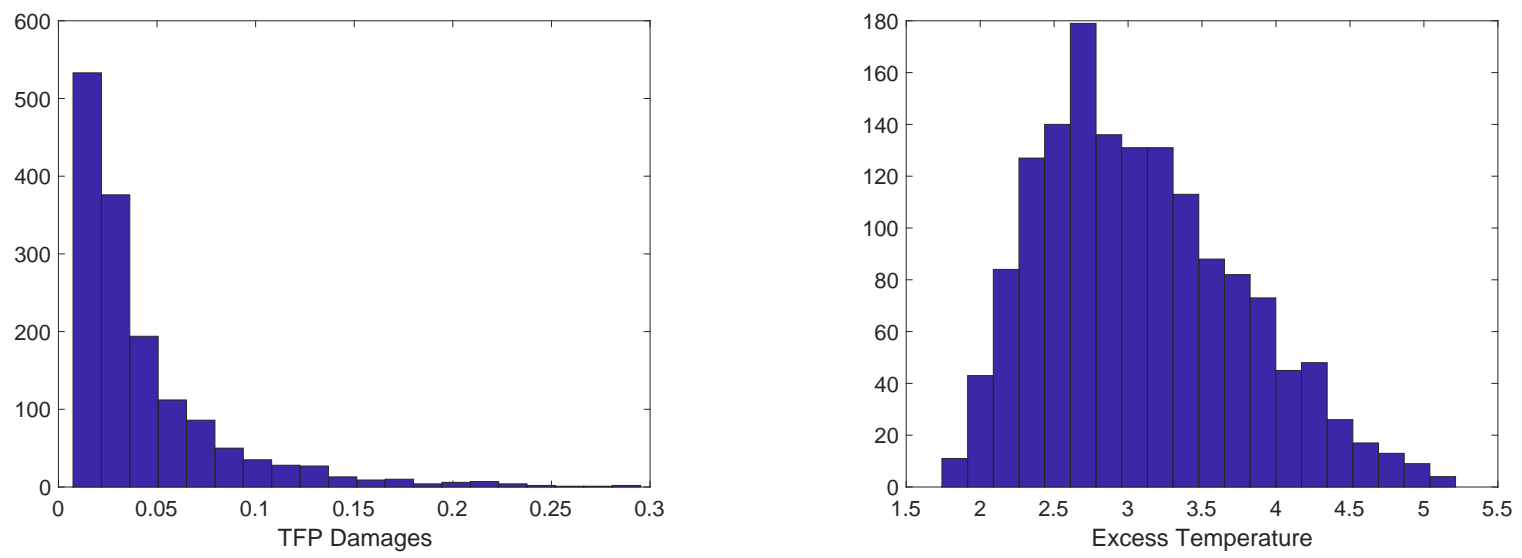

Figure 3: Distribution of damages and temperatures after 200 years.
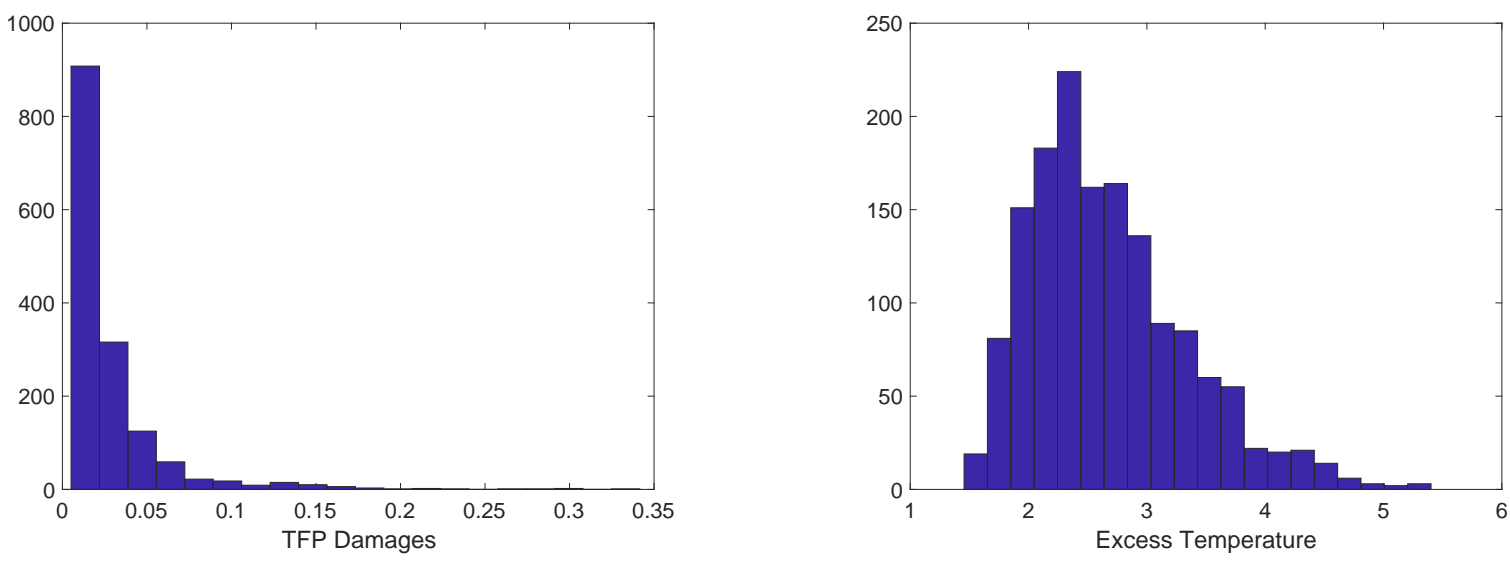

Figure 4: Distribution of damages and temperatures after 500 years.

green energy can be delayed for many periods, catastrophic damages are possible after 40 periodsthat is, 200 years. Figure 3 shows that the worst-case scenario, after 200 years, corresponds to an almost 30 percent reduction in GDP. After 500 years, there is visible recovery and damages are very small with a high probability. However, some of the worst-case scenarios still lead to 
significant damages as well as large long-run increases in temperature. When consumption disasters arise, which happens roughly 1 percent of the time, they typically last several decades and reduce aggregate consumption by much more than one third. However, in this specification, none of these consumption disasters turn out to be permanent. This reflects our assumption that only about 60 percent of $\mathrm{CO} 2$ in the atmosphere is permanent, with the remaining 40 percent depreciating slowly over time.

\subsection{Optimal carbon policy with energy usage shocks}

This subsection considers optimal carbon policy assuming just one shock, namely the shocks to the decline of dirty-energy usage specified above. Our optimal, fixed carbon tax-rate calculation generates a rate of $\tau=0.25$ - that is, a 25 percent tax on dirty energy. With this tax rate, generations born 200 years into the future gain 1.5 percent in consumption equivalence. Current generations, as well as generations in the near future, gain about 0.1 to 0.5 percent. After roughly 125 years - that is, in 25 model periods, the welfare gains become larger, reaching their maximum of 1.5 percent in about 200 years. In about 175 years, the welfare gains are roughly 1.3 percent. Climate disasters become very unlikely with a probability below 0.5 percent. ${ }^{16}$

Figures 5, 6 and 7 show that temperatures after 100 years, and, in particular, after 200 and 500 years are clearly lower than in the BAU case, leading to smaller damages. The shift in temperature appears small at first but, given our form of the damage function, in the high-temperature ranges, small temperature differences make a significant difference with regard to damage.

Clearly, Pareto-improving carbon-risk taxes do not, in this case, entirely prevent deleterious climate change. In particular, significant losses after 200 years and even after 500 years are possible, with temperature increases that are often far beyond that agreed in the Paris Accord. Even higher carbon taxes would limit this problem. However, levying them requires compensating current generations by extracting higher payments from future generations. Unless such payments were state-contingent, they would be imposed on generations born into states with significant climate damages. We leave for further research the degree to which state- and generation-contingent net taxes can further mitigate climate change.

\footnotetext{
${ }^{16}$ In 5000 simulated paths, only one climate disaster occurred.
} 

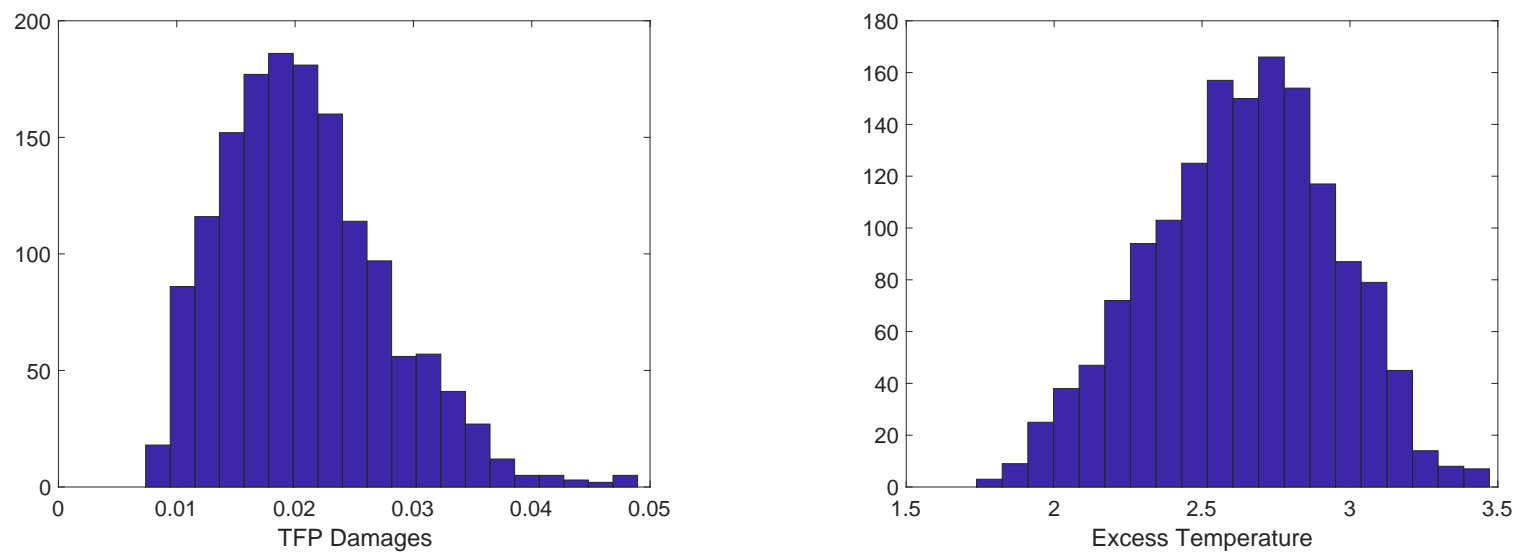

Figure 5: Distribution of damages and temperature after 100 years.
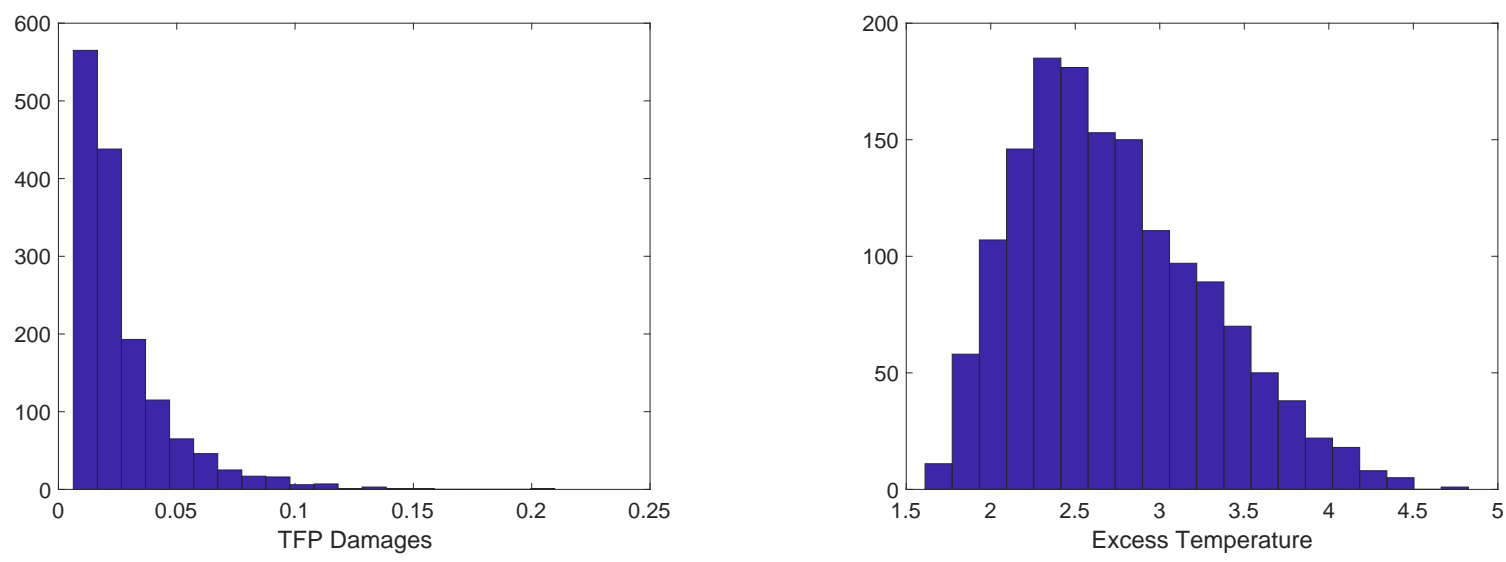

Figure 6: Distribution of damages and temperature after 200 years.

\section{Shocks to both dirty energy usage and temperature}

In this section, we combine uncertainty about future dirty energy usage and, thus, emissions with uncertainty about the degree to which high CO2 translates into higher temperatures. While the climate-sensitivity coefficient plays a crucial role in understanding the effects of CO2 emissions on 

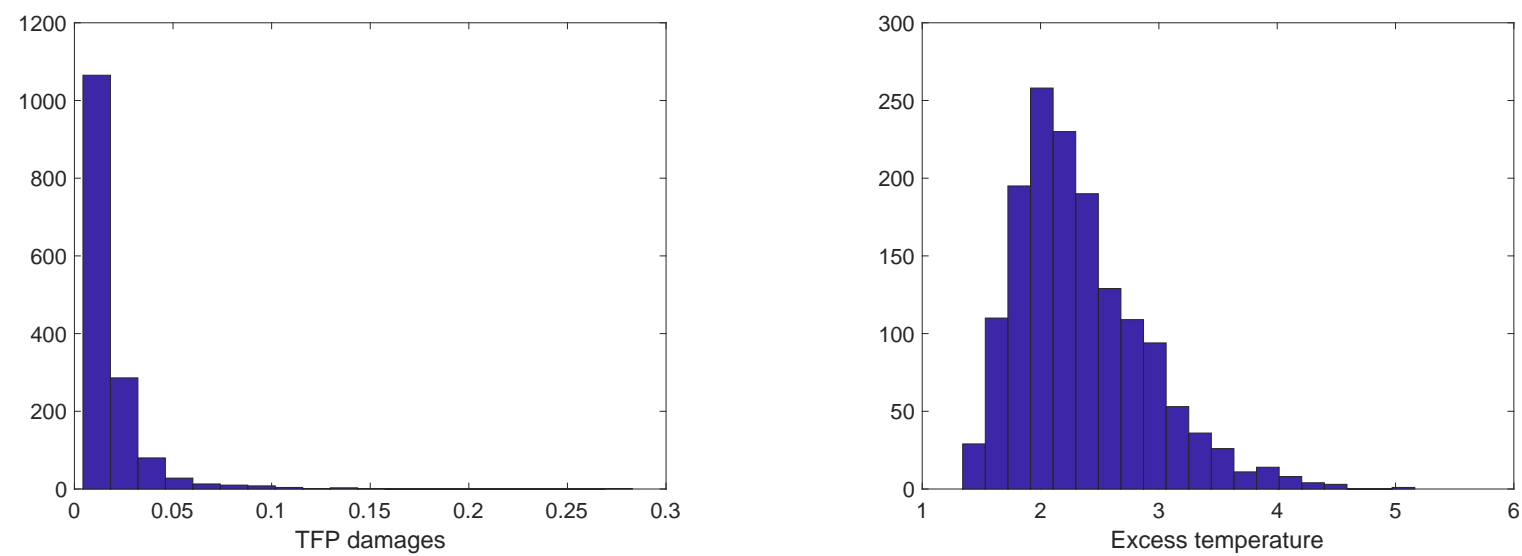

Figure 7: Distribution of damages and temperature after 500 years.

global warming, there is, unfortunately, the little scientific consensus on its value. As Knutti et al. (2017) put it, "Equilibrium climate sensitivity characterizes the Earth's long-term global temperature response to increased atmospheric CO2 concentration. It has reached almost iconic status as the single number that describes how severe climate change will be. The consensus on the likely range for climate sensitivity of 1.5 to 4.5 degrees Celsius today is the same as given by Jule Charney in 1979."

The ratio of the highest estimate to the lowest is roughly 3! A large part of this parameter uncertainty is typically attributed to model uncertainty. In other words, researchers believe that the time variation in the true parameter is much smaller than this range, but that our current climate models cannot determine this true parameter. However, there is some evidence that even beyond model-uncertainty, the equilibrium climate sensitivity varies stochastically (see, e.g., Roe and Baker (2007)) through time.

Unfortunately, our climate model (from Golosov et al. (2014)) is too simplistic to model this realistically. In order to get an idea of the impact of a stochastic climate sensitivity, we model its variation by assuming that $\lambda_{t}$ follows a random walk. Consider the following specification for shocks to $\lambda$, which translates $\mathrm{CO} 2$ levels into the forcing variable that raises the average global temperature. 
We assume that each period the shock $\epsilon_{\lambda, t}$ can take two values - that is,

$$
\epsilon_{\lambda, t}= \begin{cases}-\frac{1}{30} & \text { with prob } \frac{1}{2} \\ +\frac{1}{30} & \text { with prob } \frac{1}{2}\end{cases}
$$

We assume now that $\underline{\lambda}=0.7 \lambda_{0}, \bar{\lambda}=1.3 \lambda_{0}$ are reflecting barriers for the random walk. This specification doesn't capture all recognized uncertainty about the climate sensitivity parameter. As Forster et al. (2020) point out, this is much larger and would put the reflecting barriers well below 0.5 and well above 1.5. Hence, our calibration is highly conservative - that is, the actual uncertainty is likely much larger. ${ }^{17}$ Our results therefore constitute a lower bound on the possibility of climate disasters.

\subsection{Business as usual with dirty energy usage and temperature shocks}

As above, we first compute the equilibrium for an economy with no carbon taxes. Figures 8, 9, and 10 show the distribution of TFP-damages and temperature for the periods 20 (100 years), 40 (200 years), and 100 (500 years).

It's clear from comparing figures 8, 9, and 10 with figures 2, 3, and 4 from above, that the tails become larger. After 200 years, extreme temperatures and extreme damages now occur much more frequently ${ }^{18}$. Furthermore, after 500 years, i.e., in the very long run, substantial damages can persist.

Note that the histograms do not show the fact that with a time-varying climate sensitivity parameter, output, and aggregate consumption become very volatile when the CO2 concentration in the atmosphere is high. Given our specification of the damage functions, an increase in the climate sensitivity from $\underline{\lambda}$ to $\bar{\lambda}$ changes the temperature by more than 60 percent, which can change the damages from relatively small to quite large when the initial excess temperature is above 3 degrees. Using our specifications here, climate disasters occur frequently. In about 5 percent of the cases, aggregate consumption drops by more than one third. These drops typically last more than 100 years, in some cases, up to 350-400 years, and in some cases forever.

\footnotetext{
${ }^{17}$ However, much of it is model uncertainty which we cannot describe without having an explicit model of how this parameter is learned over time.

${ }^{18} \mathrm{It}$ is important to note that the scales differ across the examples.
} 

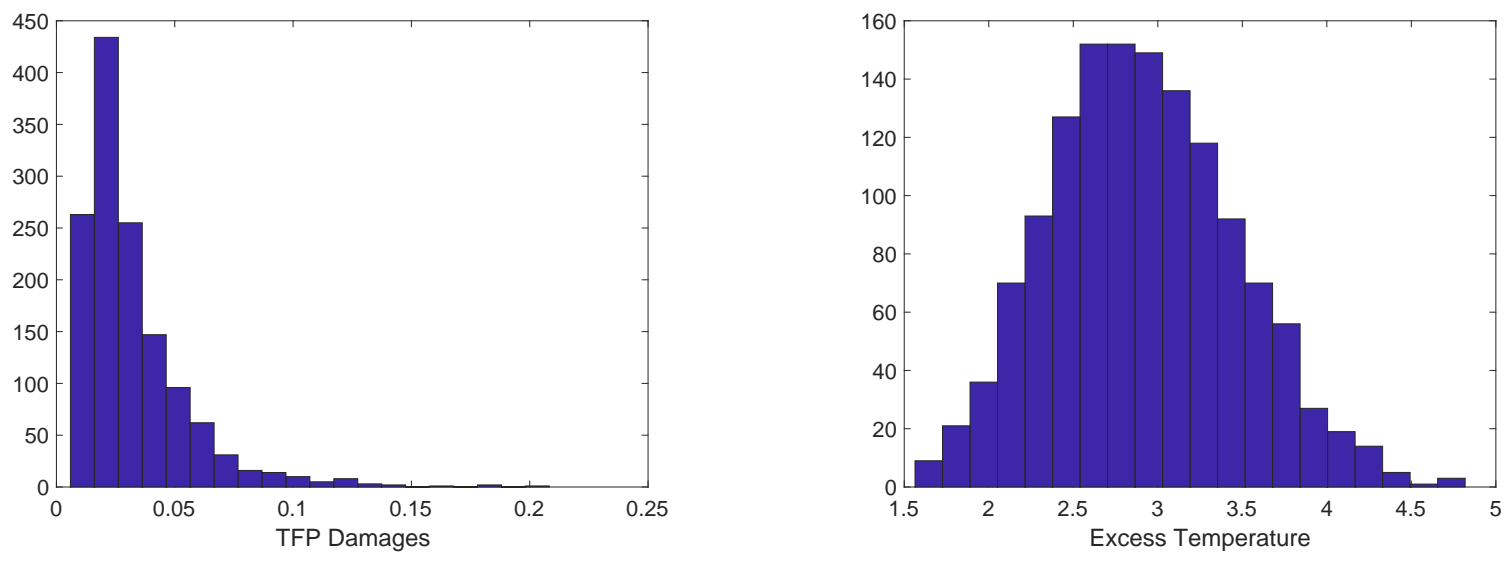

Figure 8: Distribution of damages and temperature after 100 years.
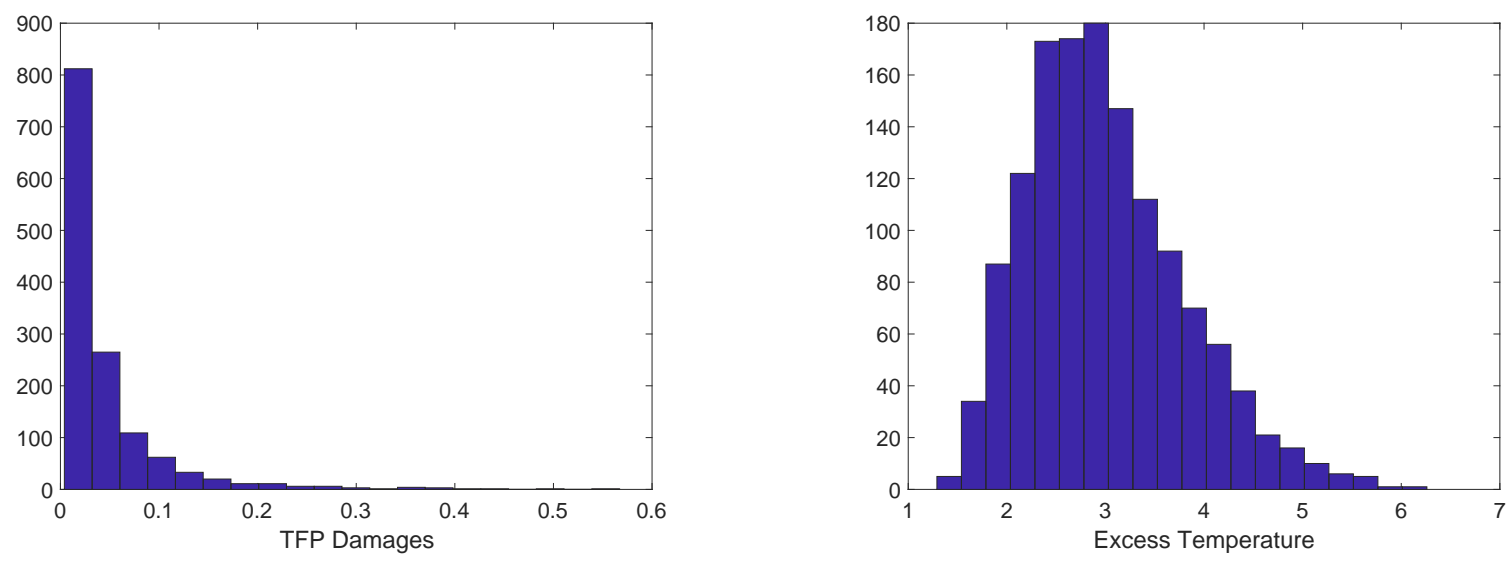

Figure 9: Distribution of damages and temperature after 200 years.

Weitzman (2009) and Weitzman (2012) describe scenarios where the said uncertainties can lead to catastrophic outcomes of climate change. However, unlike Weitzman (2009), the events in our model are not climate catastrophes that push expected utility to minus infinity. In our calibration, aggregate consumption never drops by more than two thirds. Since this happens with relatively low 

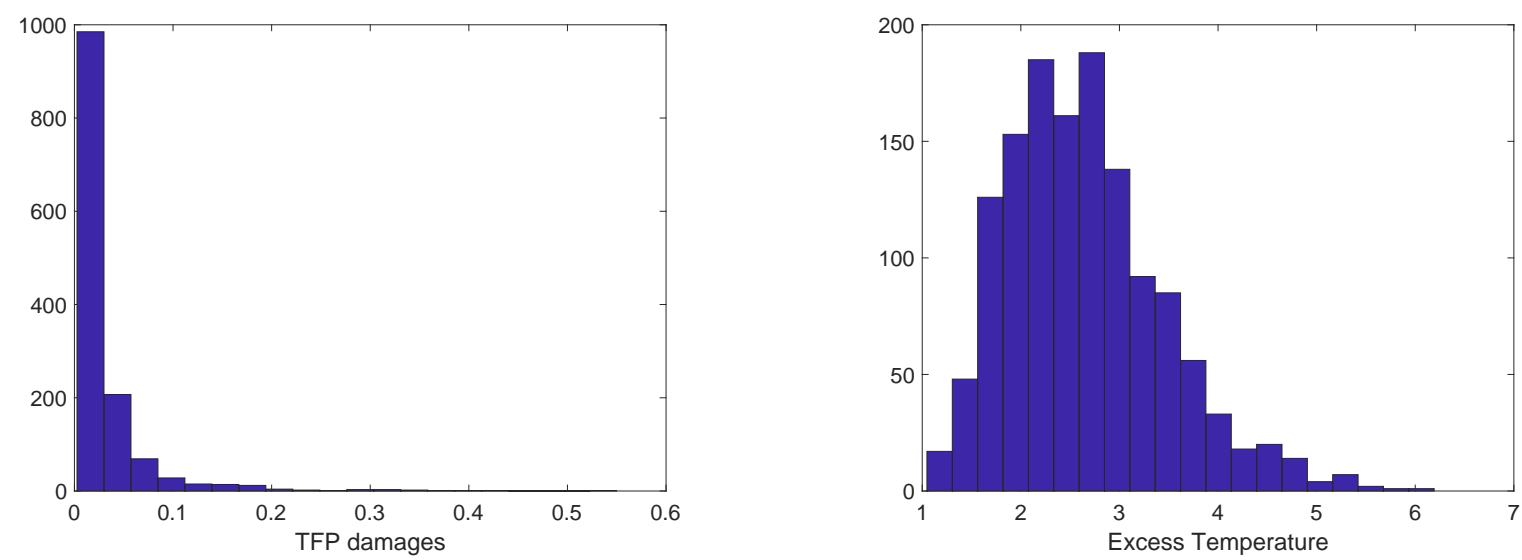

Figure 10: Distribution of damages and temperature after 500 years.

probability, the effect on average/expected utility is modest - that is, it drops, measured in certainty equivalents, by around 5 percent for some generations in the future.

\subsection{Optimal carbon policy with energy usage and temperature shocks}

As in the previous numerical example, the fact that aggregate consumption can decrease substantially in the future does not necessarily mean that higher taxes today are feasible if current generations need to be compensated. The fact that in 500 or even 1000 years, economic damages can be dramatic offers little guidance on how to achieve a Pareto improvement today.

In this two-shock case, the "optimal" fixed tax rate on dirty energy is 20 percent tax. Generations born 150 years from now or even later gain about 2 percent in certainty equivalence, and the probability of a climate disaster is reduced from more than 5 percent to around 2.5 percent.

Note that this carbon tax is 5 percent lower than the one we found above for the case of no climate uncertainty. The reason for this is that for generations born within the first five periods, an increase in precautionary savings that is caused by climate uncertainty counteracts the negative effects of the extra uncertainty, and they can no longer be compensated for facing a tax rate of 25 percent. 


\section{Three sources of risk}

This section incorporates all three shocks. To model the stochastic damage function, we assume that each period the shock $\epsilon_{T P, t}$ can realize two values - that is,

$$
\epsilon_{T P, t}=\left\{\begin{aligned}
-\frac{1}{10} & \text { with prob } \frac{1}{2} \\
+\frac{1}{10} & \text { with prob } \frac{1}{2}
\end{aligned}\right.
$$

Moreover, we assume that $\overline{T P}=2.5$ and $\underline{T P}=3.5$ are reflecting barriers for the random walk. As explained above, when current excess temperature reaches $T P$, the random walk stops as that value. If the current tipping point is at 2.5 when the excess temperature reaches 2.5 degrees, very significant damage is likely to result. If the current temperature never reaches the tipping point, the damages are quite small.

While it seems clear that there are large uncertainties about economic damages from higher temperatures, there is no unambiguous way to model them. As mentioned in the introduction, Golosov et al. (2014) follow a somewhat similar strategy to ours and assume uncertainty about a coefficient in the damage function. However, in their approach, all uncertainty is resolved at some given future date, $T$. At $T$, their coefficient randomly takes one of two values, and before $T$, their coefficient is set to the average of these two values. It seems more realistic to have the values evolve stochastically over time.

Without carbon taxation, our three-shock model results in significant damages with fairly high probability. Figures 11, 12, and 13 show the distribution of TFP-damages and aggregate consumption losses for the periods 20 (corresponding to a duration of 100 years), 40 (200 years), and 100 (500 years). Since the temperature itself is not as meaningful, given the uncertainty in the damage function, we depict the distribution of aggregate consumption losses instead. The figures are normalized in such a way that aggregate consumption at $\mathrm{t}=0$ is 1 .

Compared to the figures 2 and 10 from above, one can see significant differences in damages. With this third source of uncertainty, the probability of climate disasters now increases to about 9 percent $^{19}$ compared to 5 percent in the model without a stochastic tipping point in the damage

\footnotetext{
${ }^{19}$ Note that in the figures presented here, the frequency of a climate disaster seems significantly lower than 9 percent. This is due to the fact that the climate sensitivity parameter follows a random walk and along some paths the economy
} 

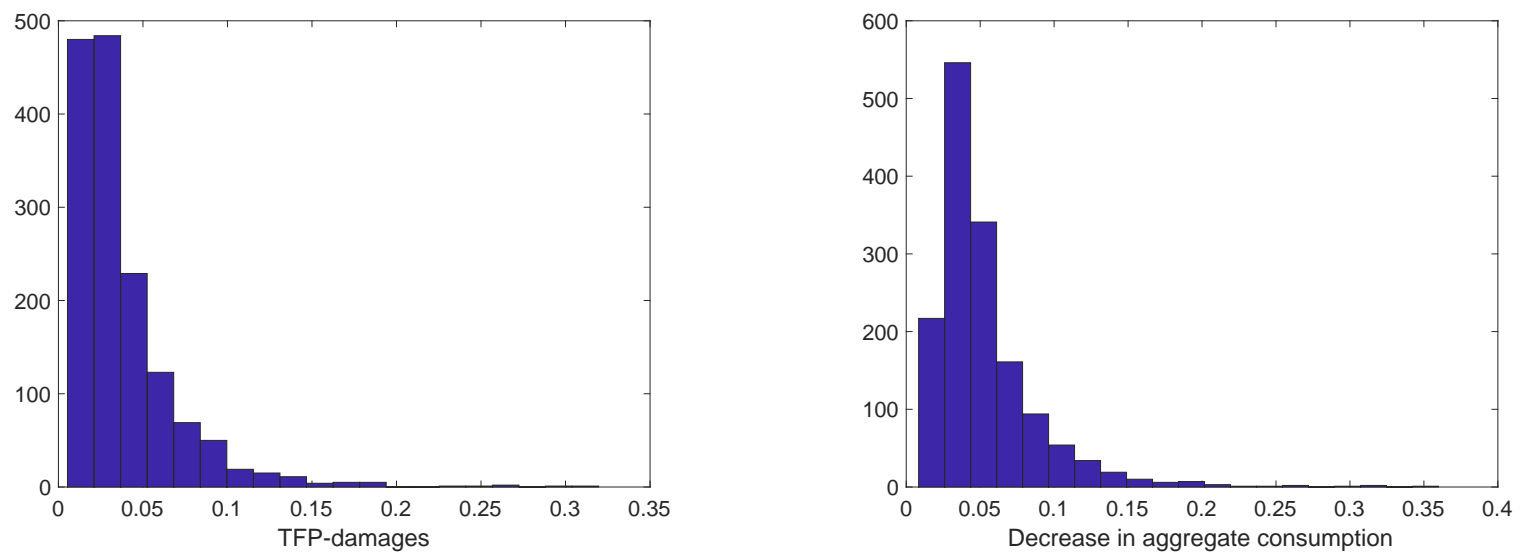

Figure 11: Distribution of damages and aggregate consumption losses after 100 years.
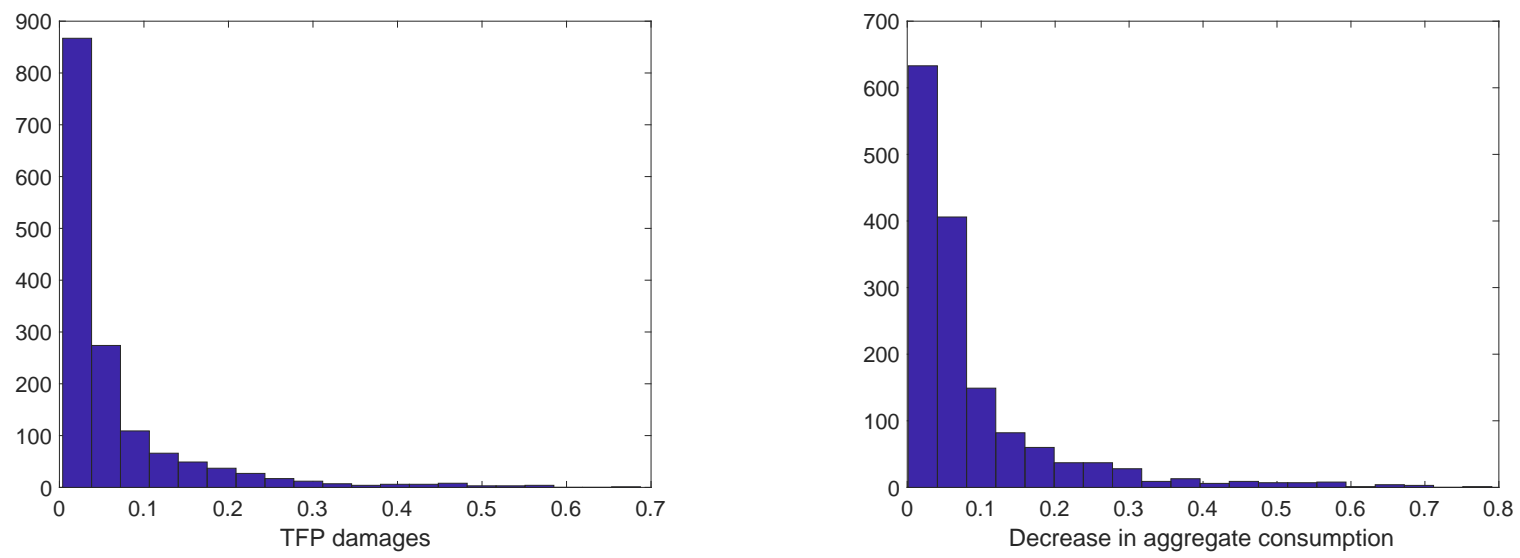

Figure 12: Distribution of damages and aggregate consumption losses after 200 years.

function. As in the case in section 5, most disaster periods last for more than 100 years and many for more than 500 years. In this model, declines in aggregate consumption of almost 80 percent become possible, even though they are unlikely. In the BAU scenario, some future generations are born into experiences transitory climate disasters, i.e., many climate disasters only occur before year 200 and many only after year 200. 

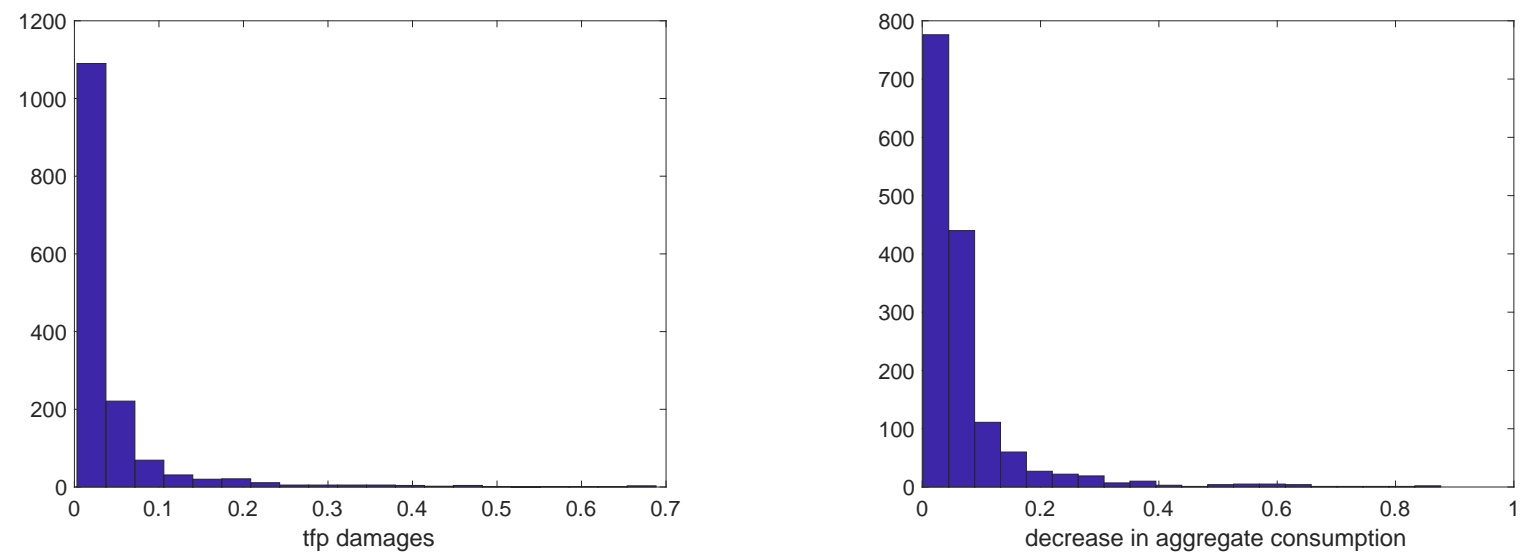

Figure 13: Distribution of damages and aggregate consumption losses after 500 years.

catastrophic economies.

The level of climate risk we model in this section now also decreases average future utilities significantly. Generations that are born in 200 years from now have, in consumption equivalents, a seven percent lower expected utility than generations born today.

\subsection{Optimal carbon policy with all three shocks}

Since lower tipping points, and hence large damages become possible, substantial damages from climate change can occur earlier in the model, making a larger initial tax feasible. With a fixed tax of 35 percent, we find that the average welfare of generations born 200 years in the future increases (in consumption equivalents) by around 4 percent. The probability of climate disasters decreases to around 3.5 percent. Hence there is still substantial climate disaster risk, which cannot be prevented by a constant tax rate.

It is useful to compare the taxes in the specification of the model with three sources of uncertainty to optimal taxes in a deterministic model. In this thought experiment we focus on the model with much more significant damages to illustrate the role of uncertainty in the damage function. For this, we consider the calibration from section 3.1 (the 'deterministic benchmark case'), but multiply 
damages by a factor of 4 - that is, the damage function becomes

$$
D_{t}=1-\frac{4}{1+\left(\frac{1}{20.46} T_{t}^{A}\right)^{2}+\left(\frac{1}{2 T P_{t}} T_{t}^{A}\right)^{6.754}}
$$

This shifts up the damages in Figure 1 above by approximately a factor of 4 (not exactly because more significant damages lead to a decrease in production and CO2 emissions) resulting in substantial damages after 20 model periods. The Pareto-improving fixed tax rate that leads to the largest

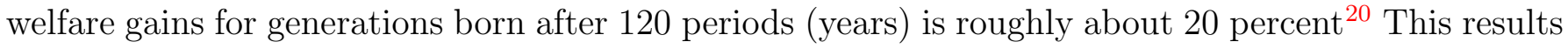
in maximal welfare gains of about 1.5 percent for generations born after 110 years. This thought experiment illustrates the significant quantitative effects of uncertainty. In a world of certainty, even if damages are four times larger than in typical calibrations, taxes and welfare gains are still relatively small.

\subsection{Carbon dependent taxes}

If we allow taxes to vary over time and with the level of atmospheric carbon, we reduce the risk of climate disasters even further by increasing the tax when CO2 concentration in the atmosphere increases substantially. In order to keep the tax Pareto-improving, one needs to start with a substantial initial tax and start increasing the tax relatively late when future generations already benefit from the initial tax.

Note that in the presence of a stochastic damage function, it might not be sufficient to control the concentration of $\mathrm{CO} 2$ in the atmosphere since a low tipping point might result in significant damages. Moreover, imposing high carbon taxes once the CO2 concentration has reached a certain level might itself lead to consumption disasters. In the presence of significant damages, these taxes push aggregate consumption down further.

The "best"specification we could find imposes additional taxes earlier than above and increases

\footnotetext{
${ }^{20}$ Note that this is still a much lower carbon tax than what is optimal in realistically calibrated models with growth and intergenerational transfers.
} 


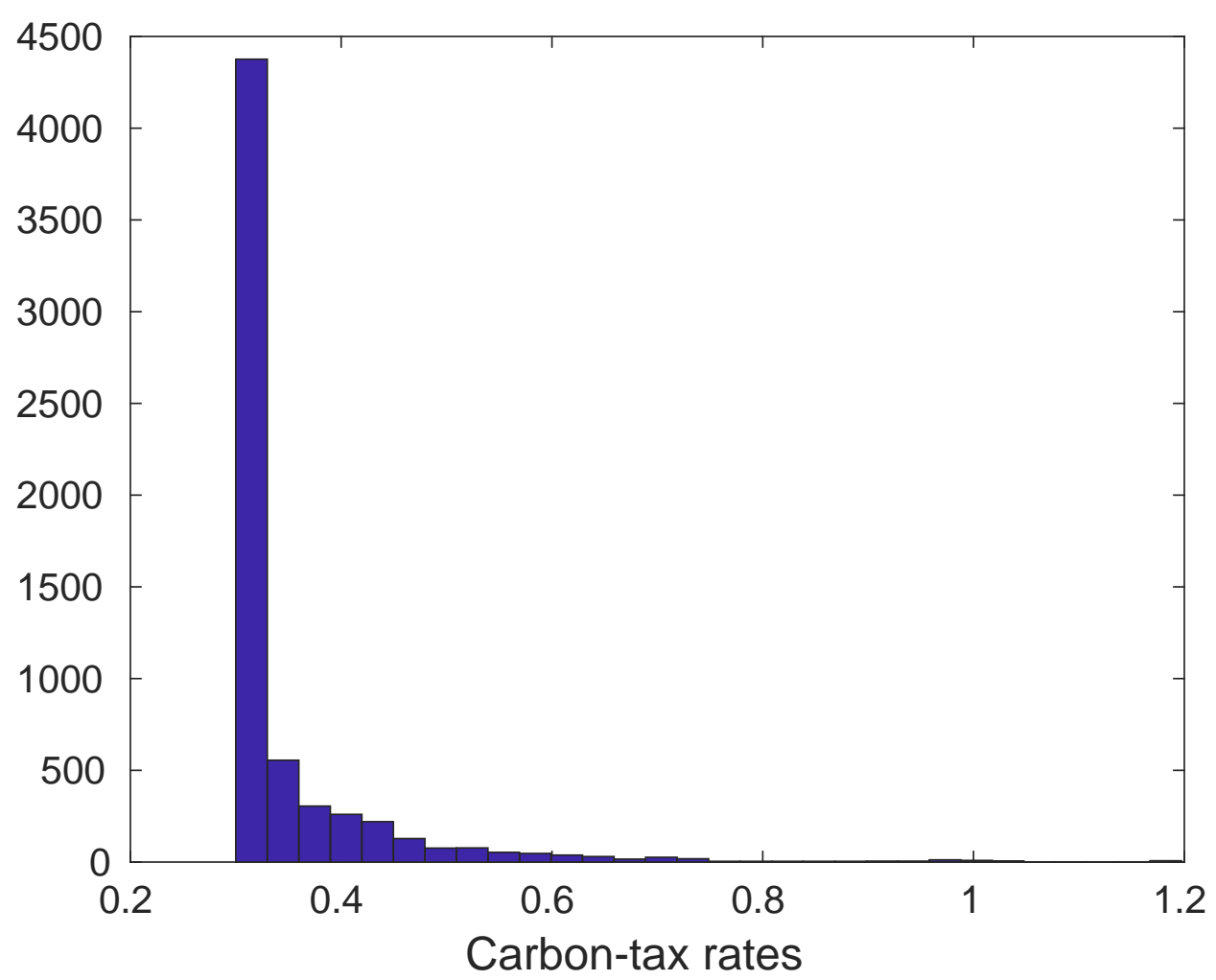

Figure 14: Distribution of carbon tax-rates.

taxes very steeply once CO2 concentration has reached a given level. We set

$$
\tau_{t}=0.3+\frac{1}{10} \max \left(0, \frac{\log \left(S_{t} / S\right)}{\log (2)}-2\right)^{3},
$$

where $S_{t}$ denotes the total amount of $C O 2$ in the atmosphere.

Observe that taxes start increasing if the excess temperature (at a climate sensitivity of 3 ) is 2 degrees. Moreover, at a temperature increase (again with $\lambda=3$ ) of more than 3 degrees, taxes start rising very rapidly. Along some paths, carbon-risk taxes increase to over 100 percent.

In Figure 14 we depict the carbon tax rates for the periods where they are relevant (i.e. $\gamma_{t}<1$ ) for 600 simulated periods. The histogram shows that in the vast majority of periods taxes are 30 percent and therefore slightly lower than the optimal fixed tax of 35 percent above. However, it often increases to more than 35 percent and in some cases well beyond that.

Using this specification, the probability of climate disaster is reduced to around 1.3 percent and hence to a much lower level than with a fixed tax. However, the welfare gains for future generations are very similar to the case of a fixed tax. Generations born in around 150 later gain slightly less (because some agents are born into economies that still use much dirty energy and hence suffer from 
higher taxes), generations born after 250 years gain slightly more, but the differences are below 0.5 percent.

To decrease this likelihood even further, one could consider a tax rate that changes according to variables other than $\mathrm{CO} 2$ concentration. However, it seems unrealistic to make the tax rate dependent on the tipping point - after all, our modeling strategy is a simplified version of a model where agents do not know the tipping point and learn it when it happens. After the tipping point is reached, it is undoubtedly too late to increase taxes.

\section{Conclusion}

This paper examines the role of uncertainty in optimal carbon taxation. We argue that starting from a model without uncertainty, the introduction of mean-preserving shocks can lead to significant and long-lasting damages. Even with modest degrees of risk aversion, the welfare loss of future generations can be significant, and climate disasters can be quite frequent. Carbon-risk taxes can achieve Pareto improvements, and if they increase at a sufficient rate with CO2 concentration, they can prevent climate disasters.

Although many aspects of the model are roughly calibrated, the parameters that we choose for the relevant stochastic processes are very "conservative" in the sense that the true uncertainty is likely to be much larger. Hence, our results provide lower bounds on possible damages and on improving carbon taxes. Finally, we show that carbon-risk tax rates can be as large, if not larger, than carbon average-damage tax rates depending on what intergenerational policies are feasible.

\section{References}

Abel, A. and Kotlikoff, L. J. (1994). Intergenerational altruism and the effectiveness of fiscal policy: New tests based on cohort data. Savings and bequests, pages 31-42.

Acemoglu, D., Akcigit, U., Hanley, D., and Kerr, W. (2016). Transition to clean technology. Journal of Political Economy, 124(1):52-104.

Allen, M. R. and Frame, D. J. (2007). Call off the quest. Science, 318(5850):582-583. 
Altig, D., Auerbach, A. J., Kotlikoff, L. J., Smetters, K. A., and Walliser, J. (2001). Simulating Fundamental Tax Reform in the United States. American Economic Review, pages 574-595.

Altonji, J. G., Hayashi, F., and Kotlikoff, L. J. (1992). Is the extended family altruistically linked? direct tests using micro data. The American Economic Review, pages 1177-1198.

Altonji, J. G., Hayashi, F., and Kotlikoff, L. J. (1997). Parental altruism and inter vivos transfers: Theory and evidence. Journal of political economy, 105(6):1121-1166.

Auerbach, A. J. and Kotlikoff, L. J. (1987). Dynamic fiscal policy. Cambridge University Press.

Barnett, M., Brock, W., and Hansen, L. P. (2020). Pricing uncertainty induced by climate change. The Review of Financial Studies, 33(3):1024-1066.

Barro, R. J. and Ursua, J. F. (2008). Consumption disasters in the twentieth century. American Economic Review, 98(2):58-63.

Bernheim, B. D. and Bagwell, K. (1988). Is everything neutral? Journal of Political Economy, $96(2): 308-338$.

Blanchard, O. (2019). Public debt and low interest rates. American Economic Review, 109(4):11971229.

Bovenberg, A. and Heijdra, B. J. (1998). Environmental tax policy and intergenerational distribution. Journal of Public Economics, 67(1):1-24.

Bovenberg, A. L. and Heijdra, B. J. (2002). Environmental abatement and intergenerational distribution. Environmental and Resource Economics, 23(1):45-84.

Brock, W. A. and Hansen, L. P. (2017). Wrestling with uncertainty in climate economic models. working paper.

Burton, P. S. (1993). Intertemporal preferences and intergenerational equity considerations in optimal resource harvesting. Journal of Environmental Economics and Management, 24(2):119-132.

Cai, Y. (2020). The role of uncertainty in controlling climate change. arXiv preprint arXiv:2003.01615. 
Cai, Y., Brock, W., Xepapadeas, A., and Judd, K. (2018). Climate policy under cooperation and competition between regions with spatial heat transport. Technical report, National Bureau of Economic Research.

Cai, Y., Judd, K. L., and Lontzek, T. S. (2013). The social cost of stochastic and irreversible climate change. Technical report, National Bureau of Economic Research.

Daniel, K. D., Litterman, R. B., and Wagner, G. (2019). Declining co2 price paths. Proceedings of the National Academy of Sciences, page 201817444.

Forster, P. M., Maycock, A. C., McKenna, C. M., and Smith, C. J. (2020). Latest climate models confirm need for urgent mitigation. Nature Climate Change, 10(1):7-10.

Gerlagh, R. and Keyzer, M. A. (2001). Sustainability and the intergenerational distribution of natural resource entitlements. Journal of Public Economics, 79(2):315-341.

Gerlagh, R. and van der Zwaan, B. (2001). The effects of ageing and an environmental trust fund in an overlapping generations model on carbon emission reductions. Ecological Economics, 36(2):311326.

Gillingham, K., Nordhaus, W. D., Anthoff, D., Blanford, G., Bosetti, V., Christensen, P., McJeon, H., Reilly, J., and Sztorc, P. (2015). Modeling uncertainty in climate change: A multi-model comparison. Technical report, National Bureau of Economic Research.

Golosov, M., Hassler, J., Krusell, P., and Tsyvinski, A. (2014). Optimal taxes on fossil fuel in general equilibrium. Econometrica, 82(1):41-88.

Heijdra, B. J., Kooiman, J. P., and Ligthart, J. E. (2006). Environmental quality, the macroeconomy, and intergenerational distribution. Resource and Energy Economics, 28(1):74-104.

Howarth, R. B. (1991a). Intergenerational competitive equilibria under technological uncertainty and an exhaustible resource constraint. Journal of Environmental Economics and Management, $21(3): 225-243$. 
Howarth, R. B. (1991b). Intertemporal equilibria and exhaustible resources: an overlapping generations approach. Ecological Economics, 4(3):237-252.

Howarth, R. B. and Norgaard, R. B. (1990). Intergenerational resource rights, efficiency, and social optimality. Land Economics, 66(1):1-11.

Howarth, R. B. and Norgaard, R. B. (1992). Environmental valuation under sustainable development. American Economic Review, 82(2):473-477.

Jensen, S. and Traeger, C. P. (2014). Optimal climate change mitigation under long-term growth uncertainty: Stochastic integrated assessment and analytic findings. European Economic Review, $69: 104-125$.

John, A., Pecchenino, R., Schimmelpfennig, D., and Schreft, S. (1995). Short-lived agents and the long-lived environment. Journal of Public Economics, 58(1):127-141.

Judd, K., Maliar, L., and Maliar, S. (2011). Numerically stable stochastic simulation approaches for solving dynamic economic models. Quantitative Economics, 2:173-210.

Kavuncu, Y. O. and Knabb, S. D. (2005). Stabilizing greenhouse gas emissions: assessing the intergenerational costs and benefits of the Kyoto Protocol. Energy Economics, 27(3):369-386.

Knutti, R., Rugenstein, M. A., and Hegerl, G. C. (2017). Beyond equilibrium climate sensitivity. Nature Geoscience, 10(10):727-736.

Kotlikoff, L. J. (1983). Altruistic linkages within the extended family, a note. Sloan Foundation Proposal.

Kotlikoff, L. J., Kubler, F., Polbin, A., Sachs, J. D., and Scheidegger, S. (2019). Making carbon taxation a generational win win. Technical report, National Bureau of Economic Research.

Krueger, D. and Kubler, F. (2006). Pareto-improving social security reform when financial markets are incomplete!? American Economic Review, 96(3):737-755.

Krusell, P. and Smith, Jr, A. A. (1998). Income and wealth heterogeneity in the macroeconomy. Journal of Political Economy, 106(5):867-896. 
Kubler, F. and Scheidegger, S. (2019). Self-justified equilibria: Existence and computation. Available at $S S R N 3494876$.

Lemoine, D. and Traeger, C. P. (2016). Economics of tipping the climate dominoes. Nature Climate Change, 6(5):514.

Marcet, A. (1988). Solution of nonlinear models by parameterizing expectations. Technical report, Carnegie Mellon University.

Marcet, A. and Lorenzoni, G. (2001). The parameterized expectations approach: Some practical issues. In Marimon, R. and Scott, A., editors, Computational Methods for the Study of Dynamic Economies. Oxford University Press, Chicago.

Marcet, A. and Marshall, D. A. (1994). Solving nonlinear rational expectations models by parametrized expectations: Convergence to Stationary Solutions. Discussion paper 91, Federal Reserve Bank of Minneapolis.

Marini, G. and Scaramozzino, P. (1995). Overlapping generations and environmental control. Journal of Environmental Economics and Management, 29(1):64-77.

Nordhaus, W. D. (2008). A Question of Balance: Weighing the Options on Global Warming Policies. Yale University Press, New Haven, CT.

Nordhaus, W. D. (2015). Climate clubs: overcoming free-riding in international climate policy. The American Economic Review, 105(4):1339-1370.

Nordhaus, W. D. (2017). Revisiting the social cost of carbon. Proceedings of the National Academy of Sciences, page 201609244.

Pecchenino, R. and John, A. (1994). An overlapping generations model of growth and the environment. The Economic Journal, 104(427):1393-1410.

Roe, G. H. and Baker, M. B. (2007). Why is climate sensitivity so unpredictable? Science, 318(5850):629-632. 
Traeger, C. P. (2019). Ace-analytic climate economy (with temperature and uncertainty). Working paper.

Weitzman, M. L. (2009). On modeling and interpreting the economics of catastrophic climate change. The Review of Economics and Statistics, 91(1):1-19.

Weitzman, M. L. (2012). Ghg targets as insurance against catastrophic climate damages. Journal of Public Economic Theory, 14(2):221-244. 